\title{
Analysis of ribosomal RNA intergenic spacer (IGS) sequences in species and populations of Gyrodactylus (Platyhelminthes: Monogenea) from salmonid fish in northern Europe
}

\author{
C. O. Cunningham ${ }^{1, *}$, C. M. Collins ${ }^{1}$, G. Malmberg ${ }^{2}$, T. A. Mo $^{3}$ \\ ${ }^{1}$ FRS Marine Laboratory, PO Box 101, Victoria Road, Aberdeen AB11 9DB, UK \\ ${ }^{2}$ Department of Zoology, University of Stockholm, 10691 Stockholm, Sweden \\ ${ }^{3}$ National Veterinary Institute, Fish Health Section, PO Box 8156 Dep., 0033 Oslo, Norway
}

\begin{abstract}
The intergenic spacer (IGS) region of ribosomal RNA genes was amplified and sequenced from a variety of Gyrodactylus specimens collected from wild and farmed Atlantic salmon Salmo salar, rainbow trout Oncorhynchus mykiss, and grayling Thymallus thymallus, from various locations in Northern Europe. Phylogenetic analysis of the sequences confirmed the distinction between G. salaris Malmberg, 1957 and G. thymalli Zitnan, 1960, supporting their validity as separate species. G. salaris adapted to rainbow trout are also distinct from the parasites found on Atlantic salmon, supporting the existence of a rainbow-trout form that was initially identified on the basis of morphological differences. Analysis of the IGS did not provide good resolution of different populations of G. salaris sensu stricto, but was consistent with epidemiological evidence which indicates that introduction of the parasite to Norway was recent and limited. The IGS may be helpful in distinguishing forms of G. salaris that are pathogenic to Atlantic salmon from those that are not.
\end{abstract}

KEY WORDS: Gyrodactylus salaris - Ribosomal RNA · Intergenic spacer · IGS · Population · Genetic variation

\section{INTRODUCTION}

The monogenean parasite Gyrodactylus salaris Malmberg, 1957, has been the cause of mass mortality of Atlantic salmon Salmo salar L. in Norway since the 1970s, leading to parr mortality of over $95 \%$ and decimating populations of wild salmon in many rivers (Mo 1994). The species was originally described from an Atlantic salmon fish farm within the Baltic East coast drainages in Sweden (Malmberg 1957), but has not led to mass salmon mortality in that country (Malmberg \& Malmberg 1993). This is likely to be due, in part, to variation in resistance of different salmon races to the parasite. Variable susceptibility has been documented, and has been shown to have a genetic basis (Bakke 1991, Bakke et al. 1990, 1996, 1999). Genetic variation of salmon populations has been revealed through mitochondrial DNA studies (Nilsson et al. 2001), but genetic variability of the pathogen is also of interest, particularly from an epidemiological view.

\section{Gyrodactylus thymalli and G. salaris}

The morphological characteristics of Gyrodactylus salaris are very similar to other species of the same genus (Malmberg 1987a, Cunningham et al. 2001). There has long been discussion of whether G. salaris and G. thymalli are separate species or not (Malmberg 1987a, McHugh et al. 2000, Sterud et al. 2002). Parts of the small subunit, or $18 \mathrm{~S}$, ribosomal RNA (rRNA) gene and the internal transcribed spacer (ITS) region of the rRNA are identical in the 2 species (Cunningham 1997). This is remarkable, as the ITS shows significant 
variation, even between morphologically similar species (Cunningham et al. 2001). However, the marginal hook sickle morphology of the 2 species can be used to discriminate G. salaris and G. thymalli, and sequence variations have been found in the intergenic spacer (IGS) of the rRNA genes (Sterud et al. 2002), although it was not known how conserved the differences were between the species.

\section{The rainbow-trout form of Gyrodactylus salaris}

Gyrodactylus salaris is known to be extremely variable in morphology (Mo 1991a,b), with distinct differences among specimens collected from rainbow trout Oncorhynchus mykiss Walbaum and those from Atlantic salmon (Malmberg 1973, Mo 1991c). It has been speculated that the forms adapted to rainbow trout might also have pathogenicity and genetic differences (Malmberg 1987b), although both types are equally pathogenic to salmon in laboratory experiments (T. A. Mo unpubl.). Parts of the 18S rRNA gene and the ITS region of the rRNA are identical in the 2 forms, and they have hitherto been considered as the same species.

\section{Gyrodactylus salaris populations}

As well as in Sweden and Norway, Gyrodactylus salaris has been recorded in Finland (Rintamaki 1989) and the former Soviet Union (Ergens 1983). As previously mentioned, there appear to be considerable differences in the pathogenicity of the parasite in different regions.

In Finland, investigations have revealed the presence of Gyrodactylus salaris in many regions, including rivers draining into the Baltic Sea, White Sea and Arctic Ocean (Keranen et al. 1992, Koski \& Malmberg 1995, Rintamaki-Kinnunen \& Valtonen 1996), although no pathogenic effects have been noted. In contrast, the Russian rivers draining to the White Sea have experienced serious salmon parr mortality attributed to $G$. salaris (Ieshko et al. 1995, Shulman et al. 1998).

The status of Gyrodactylus salaris infections in Norway has received intense and systematic attention, with large-scale sampling programmes being undertaken since the emergence of this pathogen in the 1970s (Mo \& Norheim 2003).

Surveys of Gyrodactylus spp. parasites in Sweden have been carried out by the University of Stockholm, partly assisted by the Swedish Fishery Board (Malmberg 1957, 1973, 1987b, 1988, 1991, 1993, Malmberg \& Malmberg 1987, 1993). This was not a systematic examination of fish in all rivers, and no surveys were carried out on the West coast of Sweden prior to 1989, but the spread of the parasite to rivers of the Swedish West Coast has been observed since 1989 (Malmberg \& Malmberg 1991). In a few of these rivers, there may be indications of negative impacts of $G$. salaris on the density of salmon parr (Karlsson et al. 2003).

Differentiating populations of this parasite is of great interest for several reasons. The identification of intraspecific groups might enable the sources of new infections, or re-infections of rivers that have been treated, to be traced. On a longer time-scale, clues as to the spread of Gyrodactylus salaris across Northern Europe might be obtained from intra-specific variations. This spread has been promoted by the transport of live salmonids. Movement of salmon parr from an infected hatchery in Sweden to a farm in Norway, and the subsequent use of fish from this farm for restocking, are one likely main source of initial infection in Norway. The river Skibotnelva, the northernmost infected river in Norway, remote from other infected rivers, was known to be infected via smolts from a Swedish hatchery in 1975 (Jensen et al. 1983). The spread of $G$. salaris within Sweden also appears to be associated with movements of salmon and rainbow trout.

No intraspecific variation has been found in the rRNA ITS of Gyrodactylus salaris sensu stricto from Norway, Sweden, Finland, Russia and Denmark, and random amplified polymorphic DNA (RAPD), although previously used to identify genetic variations between samples from the Batnfjordselva, Lierelva and Litledalselva in Norway (Cunningham \& Mo 1997), is difficult to reproduce and employ on small samples.

The rRNA IGS, and in particular, the 2 regions of repetitive DNA within it (Collins \& Cunningham 2000), from many samples of Gyrodactylus spp. was used in this study to examine inter- and intra-specific genetic variation.

\section{MATERIALS AND METHODS}

Sample collection and microscopy. Atlantic salmon Salmo salar L. parr and grayling Thymallus thymallus L. were sampled from rivers by electrofishing and fly fishing, respectively. Rivers sampled are listed in Table 1. Farmed Atlantic salmon and rainbow trout Oncorhynchus mykiss Walbaum were collected from tanks. Gyrodactylus salaris were collected from rainbow trout at a farm west of Oslo, and some were transferred to rainbow trout or salmon in an experimental aquarium. This infection was maintained for nearly 2 yr on rainbow trout and for 2 to 3 mo on salmon parr (the short time of salmon infection being due to host mortality), until fish were sampled and parasites collected. Fish were either anaesthetised and examined 
Table 1. Gyrodactylus salaris and G. thymalli. Samples used in this study, with sequences of intergenic spacer (IGS) variable regions used for phylogenetic analysis given as letter codes. Nucleotide sequences of each letter code are detailed in Table 2. Shaded boxes indicate samples used for maximum likelihood analysis (see Fig. 2). Sources: W, wild; A, aquarium; F, farm

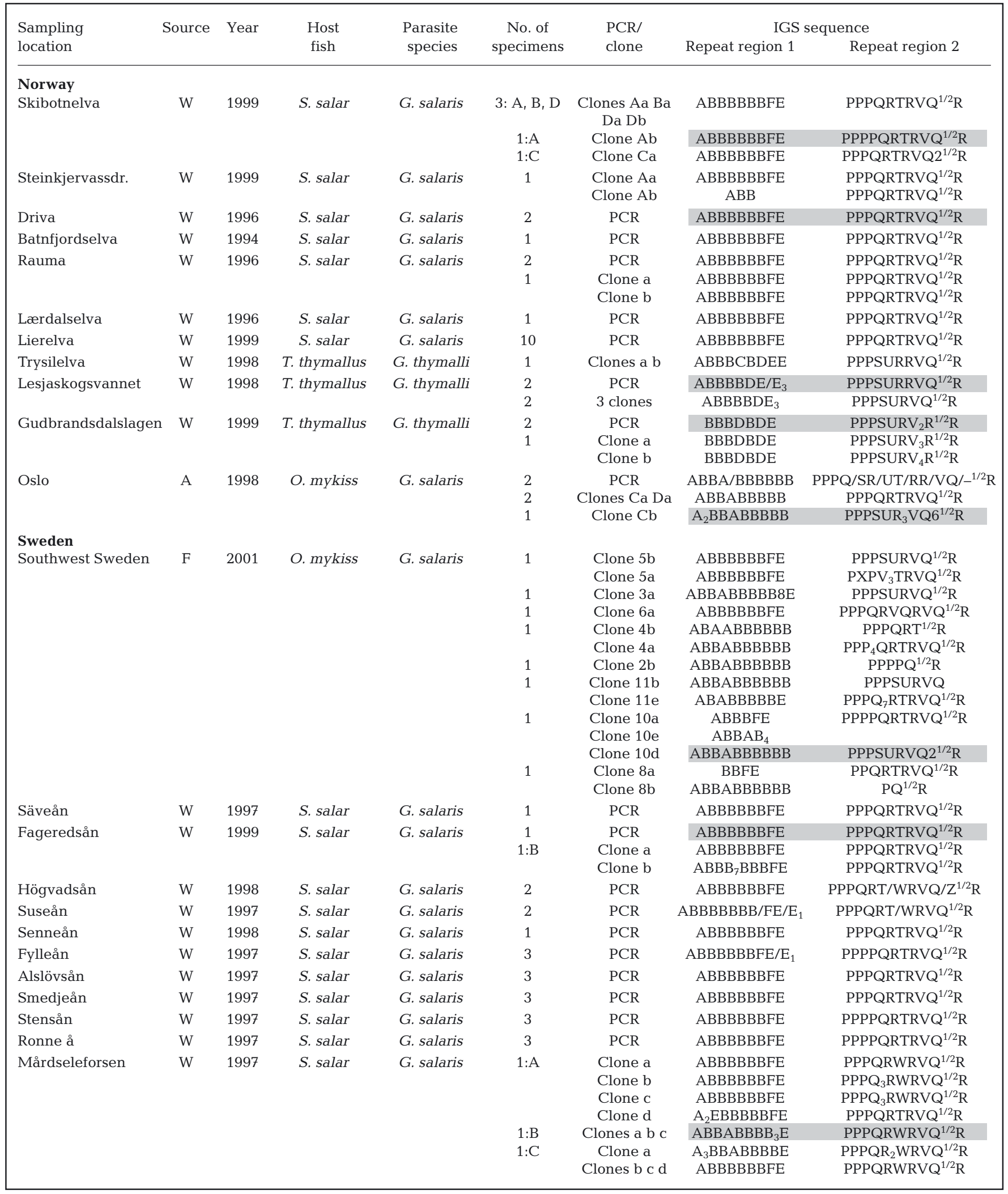


Table 1 (continued)

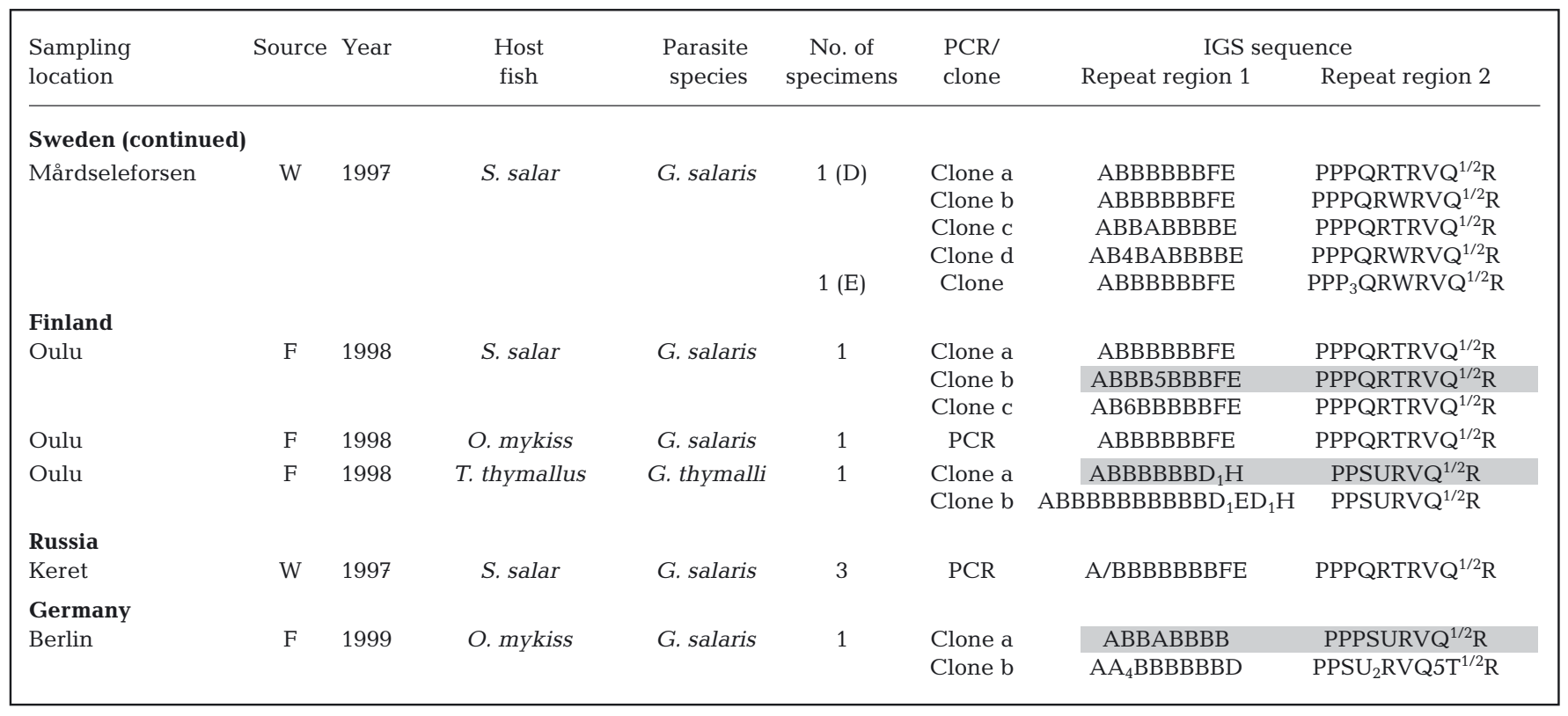

on site, or they were placed in water from the river for transport and examination in the laboratory. Fish were killed by a blow to the head and examined under a binocular microscope, then parasites were picked from the surface of the fish and placed in 70, 80 or $96 \%$ (v/v) ethanol. Individual parasites were placed on microscope slides, fixed and stained with ammonium picrate-glycerin solution (Malmberg 1970) and examined under high-power magnification (objective $90 \times$ or $100 \times)$.

DNA extraction and amplification. Other individual parasites from the same sample were placed in $7.5 \mu \mathrm{l}$ lysis buffer (Proteinase K $60 \mu \mathrm{g} \mathrm{ml}^{-1}$, NP40 0.45\%, Tween $200.45 \%$ in TrisHCl 10 mM, EDTA 1 mM, pH 8.0). The tubes were incubated at $65^{\circ} \mathrm{C}$ for $20 \mathrm{~min}$ to allow Proteinase $\mathrm{K}$ digestion of the parasite, then at $95^{\circ} \mathrm{C}$ for $10 \mathrm{~min}$ to inactivate the Proteinase $\mathrm{K}$.

Aliquots of lysate were used in amplification of both the variable region V4 of the small subunit rRNA gene and the ribosomal internal transcribed spacer, as previously described (Cunningham 1997, Cunningham et al. 1995).

Aliquots of $2.5 \mu$ lysate were used as a template in amplification reactions using primers IGSV3 (5'-CTGGCTATAATCACGTAAGACTGC-3') and IGSV4 (5'AAGATACTCATTTGACTCGGTGTG-3') which are situated in conserved regions of the Gyrodactylus salaris IGS, flanking a variable region (Collins \& Cunningham 2000). The amplification reaction contained buffer $1 \times$ (Bioline), $\mathrm{MgCl}_{2} 1.5 \mathrm{mM}$, dNTPs $0.25 \mathrm{mM}$, primers $1 \mu \mathrm{M}$ each, DNA template, and distilled water. This was denatured at $96^{\circ} \mathrm{C}$ for $5 \mathrm{~min}$ before addition of $0.5 \mathrm{U}$ Taq polymerase (Bioline) to give a final volume of $20 \mu \mathrm{l}$.

The cycling conditions were; 35 cycles of $96^{\circ} \mathrm{C}$ for $1 \mathrm{~min}, 55^{\circ} \mathrm{C}$ for $1 \mathrm{~min}, 72^{\circ} \mathrm{C}$ for $2 \mathrm{~min}$, followed by 1 cycle of $72^{\circ} \mathrm{C}$ for $10 \mathrm{~min}$. Amplification products were checked on a $1 \%$ agarose gel stained with ethidium bromide.

DNA sequencing. PCR products were purified using the Geneclean III Kit (Bio 101). Concentrations of the purified PCR products were estimated following agarose gel electrophoresis alongside mass markers (Life Technologies). PCR products were either sequenced directly or following cloning in the pGEMT vector (Promega), using the IGSV3 and IGSV4 primers, Big Dye sequencing reactions (Applied Biosystems) and electrophoresis on an ABI 377 automated sequencer (Applied Biosystems).

Sequences were checked using Sequencher 3.0 software (Gene Codes). Alignment of sequences was carried out using ClustalX (Thompson et al. 1997).

Sequence analysis. The variable area of the IGS contains 2 regions of repetitive DNA, each region consisting of between 8 and $15 \times 23 \mathrm{bp}$ sequences. The individual $23 \mathrm{bp}$ units were not identical. Each different 23 bp sequence was assigned a letter code and the sequences of these units are shown in Table 2.

Data was entered and aligned in MacClade (Maddison \& Maddison 2000), using the letter codes for the repeats or the nucleotide sequences. Identical sequences from the same location, and sequences which resulted in ambiguous alignments, were removed, as were invariant positions in the alignment.

Phylogenetic analysis was carried out using PAUP 
Table 2. Gyrodactylus salaris and G. thymalli. Sequences and letter codes for individual repeats found in the intergenic spacer (IGS)

\begin{tabular}{|c|c|c|c|}
\hline \multicolumn{2}{|r|}{ Repeat region 1} & \multicolumn{2}{|r|}{ Repeat region 2} \\
\hline Letter code & Sequence & Letter code & Sequence \\
\hline A & GTCCTTCAGTGTAGAACCGTACA & $\mathrm{P}$ & TACTAATACCGTGTAGCCGTAGG \\
\hline $\mathrm{A}_{1}$ & GTCCTTCAGTGTAGAACCGTACG & $\mathrm{P}_{3}$ & TACTAACACCGTGTAGCCGTAGG \\
\hline $\mathrm{A}_{2}$ & GTTCTTCAGTGTAGAACCGTACA & $\mathrm{P}_{4}$ & TGCTAATACCGTGTAGCCGTAGG \\
\hline $\mathrm{A}_{3}$ & GTCCTTCAGTGTAAAACCGTACA & $\mathrm{Q}$ & TATTATTACCGTAGAGCCGTACG \\
\hline $\mathrm{A}_{4}$ & GTCCTTCAGTGGAGAACCGTACA & $\mathrm{Q}_{2}$ & TATTACTACCGTAGAGCCGTACG \\
\hline B & GTCCTTCAGTGTAGAGCCGTACA & $\mathrm{Q}_{3}$ & TATTATTACCGTAGAGCCGTACA \\
\hline $\mathrm{B}_{3}$ & GTCCTTCAGTGTAGAGCCGTGCA & $Q_{5}$ & TATTATTACCGTAGAGCCGTAGG \\
\hline $\mathrm{B}_{4}$ & GTCCTTCAGTGTAGAGCCGTACG & $\mathrm{Q}_{7}$ & TATTATTACCGTAGAGCCGCACG \\
\hline $\mathrm{B}_{5}$ & GTCCTTCGGTGTAGAGCCGTACA & $\mathrm{R}$ & CACTATTACCGTGGAGCCGTAGG \\
\hline $\mathrm{B}_{6}$ & GTCCTTCAGTGAAGAGCCGTACA & $\mathrm{R}_{2}$ & CACTATTACCGTGGAGCCGTATG \\
\hline $\mathrm{B}_{7}$ & GTCCTTCAGTGTAGAGCCGCACA & $\mathrm{R}_{3}$ & CACTATTACCGTGGAGCACTAGG \\
\hline $\mathrm{C}$ & GTCCCTCAGTGTAGAGCCGTACA & S & TACTTATACTGTAGAGCCGTAGG \\
\hline D & GTCATTCAGTGTAGAGCCGTACA & $\mathrm{T}$ & TACTTATACCGTGGAGCCGTACG \\
\hline D1 & GGCATTCAGTGTAGAGCCGTACA & $\mathrm{U}$ & TACTTATACCGTAGAGCCGTACG \\
\hline E & GTCCTTTAGTGTAGAGCCGTACA & $\mathrm{U}_{2}$ & TACTTATACCGTAGAGCCGTGCG \\
\hline $\mathrm{E}_{1}$ & CTCCTTTAGTGTAGAGCCGTACA & $\mathrm{V}$ & TACTTTTACCGTGAAGCCGTAGG \\
\hline $\mathrm{E}_{3}$ & GCCCTTTAGTGTAGAGCCGTACA & $\mathrm{V}_{2}$ & TACTTTTACCGTAGAGCCGTACG \\
\hline F & GTCATTCAGGGTAGAGCCGTACA & $\mathrm{V}_{3}$ & TACTTTTACCGTGGAGCCGTAGG \\
\hline $\mathrm{H}$ & GTCCTTTAGAGTAGAGCCGTACA & $\mathrm{W}$ & TACTTATATCGTGGAGCCGTACG \\
\hline & & $\mathrm{X}$ & TACTAATACCGTGTAGCCGAAGG \\
\hline & & $\mathrm{Z}$ & TATTATTACCGTAGAGCCGTCCG \\
\hline & & ${ }^{1 / 2} \mathrm{R}$ & CACTATTACCGTGG \\
\hline
\end{tabular}

version 4.0b10 (Swofford 2002). Distance analysis was carried out using neighbor-joining/UPGMA, with both letter codes and sequences. Data were bootstrapped 1000 times and groups compatible with $50 \%$ majorityrule consensus were included. Maximum likelihood (ML) analyses were performed with selected sequences and a heuristic search strategy. Modeltest V. 3.06 was used to select the model of evolution of best fit $(\mathrm{GTR}+\mathrm{G}+\mathrm{I})$, with 100 bootstrap replicates to search for the best tree.

\section{RESULTS}

The PCR-amplified variable region V4 and ITS contained the same sequence as previously reported for Norwegian Gyrodactylus salaris (Cunningham et al. 1995, Cunningham 1997).

Repeat regions 1 and 2 of the IGS displayed variations among and within samples. There were differences in the number of repeat units found in different specimens. The sequences of each individual $23 \mathrm{bp}$ unit also varied. Some sequences of PCR products contained apparently heterozygous positions, and sequences of different clones from the same individual parasite were not always identical (Table 1). In general, the IGS sequences from Norwegian salmon para- sites were most conserved, followed by the Swedish salmon samples. Samples from rainbow trout were more diverse than those from salmon, and the samples from grayling appeared to be distinct from those from the salmon and trout.

To obtain the best alignment for ML analysis, only selected sequences were used. These are indicated by shading in Table 1. A total of 215 aligned positions were used in analysis of the nucleotide sequences. ML analyses followed a GTR+G+I model.

All phylogenetic analyses showed clear separation of the salmon form of Gyrodactylus salaris, the rainbowtrout form, and G. thymalli. These groupings were well supported, whether letter codes or sequences were analysed. Within the clade containing the salmon form of G. salaris, most groups had low support.

Where different sequences were obtained from different specimens of the same location, or from different clones from the same parasite, most grouped together (Fig. 1). Mårdseleforsen (River Vindelälven) samples yielded the most diverse sequences from the salmon form Gyrodactylus salaris. Sequences descended from G. salaris parasites from rainbow trout, which were then transferred to and maintained on salmon in the aquarium (Oslo Oncorhynchus mykiss), grouped with other specimens from rainbow trout, but not with those from salmon. 


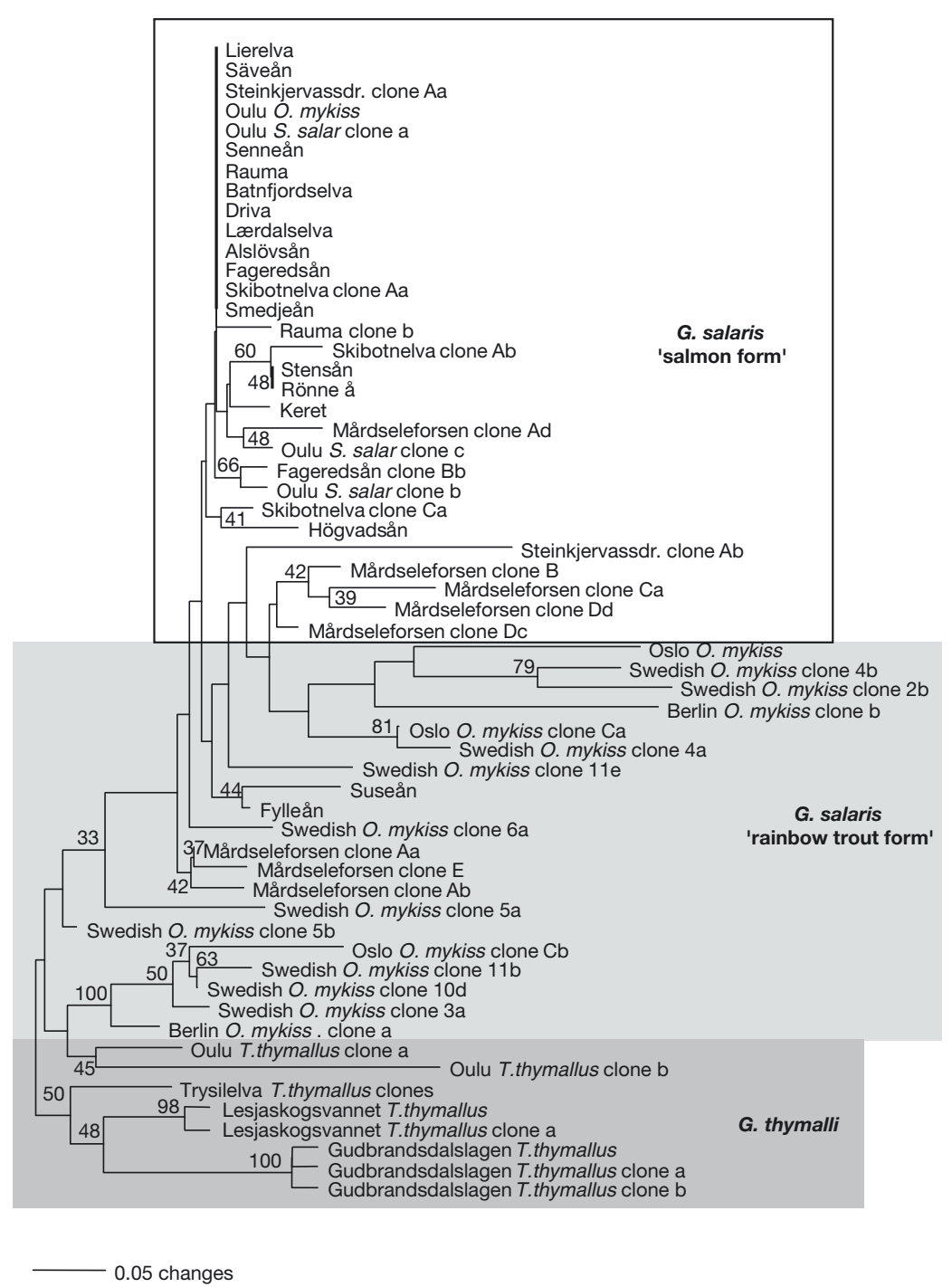

Fig. 1. Gyrodactylus salaris and G. thymalli. Phylogenetic analysis of intergenic spacer (IGS) sequences using neighbor joining/UPGMA and letter codes. Numbers at nodes indicate the support for groups to the right of the node following 1000 bootstrap replicates, where support value was greater than 30

\section{DISCUSSION}

\section{IGS sequences}

The occurrence of ambiguous sequences from PCR products, and heterogeneity of sequences in cloned products from single parasites, could indicate heterozygosity or differences in the sequences of individual IGS units within different repeat units of the rRNA genes. Examination of repetitive DNA such as this in minisatellite analysis of populations usually requires analysis of many specimens to indicate the haplotype in each population. The availability of samples restricted our ability to do this, as very few parasites, from very few fish at a single site in the river, were available. In addition, the grayling is itself a rare fish, so the opportunity for sampling many specimens, few of which may be infected and even then at very low intensity, is very limited. Despite these drawbacks, this study presents the most extensive analysis of Gyrodactylus salaris populations to date.

Because the limited availability of samples prevented analysis by population genetic algorithms (Burke et al. 1991), phylogenetic analysis of the IGS was carried out. Several sequences had to be removed for this analysis, as alignments were ambiguous; this was another disadvantage of the repetitive nature of these sequences. Phylogenetic methods may not be optimal for these sequences, and have yielded unresolved trees in analysis of other species (Morales-Hojas et al. 2002). Better

The ML tree produced following analysis of selected sequences only is shown in Fig. 2. This tree contains the same major groupings of Gyrodactylus thymalli, the rainbow-trout form of $G$. salaris, and the salmon form of $G$. salaris, with very close grouping of all salmon form $G$. salaris.

IGS sequences from Norway were the most conserved, and this is reflected in the topology of the trees in Figs. 1 \& 2. Sequences from salmon collected in Sweden tended to be more variable, but the bootstrap values for groupings within the salmon parasites were very low, even when only these sequences were analysed, with the rainbow trout and grayling specimens removed. resolution was obtained in this study, where some conclusions can be drawn from the results, and some valuable epidemiological information can be gained.

\section{Gyrodactylus thymalli and G. salaris}

Further support for the distinction between Gyrodactylus thymalli and G. salaris has been obtained from this study. These are the most genetically similar Gyrodactylus species identified to date, they are difficult to differentiate by morphology (Malmberg 1987a), and yet they have dramatically different biological effects; G. thymalli apparently causes no problems to 
Fig. 2. Gyrodactylus salaris and G. thymalli. Maximum likelihood analysis of selected intergenic spacer (IGS) sequences. Numbers at nodes indicate the support for groups to the right of the node following 100 bootstrap replicates, where support value was greater than 30

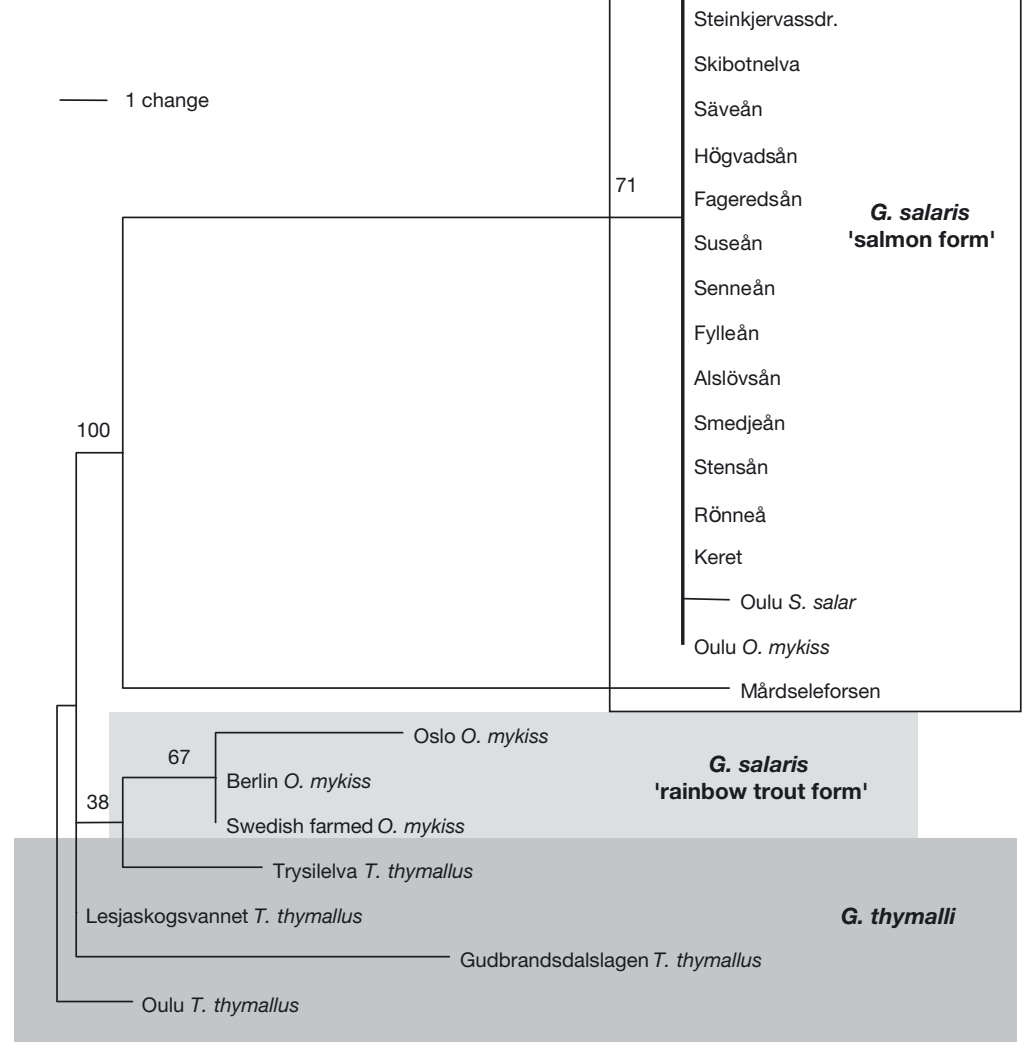

\section{The rainbow-trout form of Gyrodactylus salaris}

Morphological variations have been noted in Gyrodactylus salaris from rainbow trout when compared to those from Atlantic salmon (Malmberg \& Malmberg 1987, Mo 1991c). This parasite appears to survive and reproduce well on both hosts (Bakke 1991, Bakke et al. 1991). In the case of the parasite from rainbow trout in Finland (Oulu Oncorhynchus mykiss), it was not clear if the parasite had originated on the rainbow trout, or if it had transferred to the rainbow trout from salmon that had been kept at the farm a short time prior to sampling. The latter might explain why these parasites from Finnish rainbow trout do not group with the other rainbow trout forms, but rather, with salmon forms instead. This parasite still conforms to the type expected in parasites pathogenic to salmon, and is the same as that found from parasites on salmon at the same farm, so it seems likely that it was transferred to rainbow trout from salmon shortly before it was sampled.

The greater diversity of the IGS from rainbow trout samples compared to those from salmon was marked and reasonably well supported in phylogenetic analysis. Rainbow trout have been artificially transported throughout Scandinavia for over $100 \mathrm{yr}$ (Malmberg 1988,

either grayling or salmon, while G. salaris has caused epidemic mortality in Atlantic salmon. These 2 species share identical sequences within the 18S rRNA gene and the ITS region, a degree of similarity that is uncanny. In all other Gyrodactylus species studied to date, the ITS sequences of different species differ by genetic distances of at least $1 \%$ (Zietara \& Lumme 2003), and the lack of variation might lead one to conclude that they are strains rather than species. However, information on host preference and pathogenicity indicates that there are biologically meaningful differences between G. thymalli and G. salaris (Sterud et al. 2002). The results of the present study substantiate the work of Sterud et al. (2002), in that, in alignment, the sequences of the IGS from G. thymalli can immediately be seen to vary from those of the pathogenic G. salaris found in Norway, and these separations are well supported in phylogenetic trees. Thus, the IGS may be a suitable genetic marker to distinguish these species, and this is of great value.
Malmberg \& Malmberg 1993). Gyrodactylus salaris is commonly found on this host in both rivers and farms. Thus, it is possible that a population, or populations, of the parasite have existed on this host for many years, and during the process of adaptation have diverged significantly both at the level of the genome and morphologically. Indeed, the greater diversity found in these parasites compared to those from salmon might even suggest that the rainbow trout form is ancestral to the salmon type, but further samples should be examined, using a variety of genetic markers, before this can be supported.

Examination of the $23 \mathrm{bp}$ repetitive sequences in the IGS of rainbow trout forms of Gyrodactylus salaris reveals the presence of 2 prominent types of repeat patterns within individuals. These patterns are representative of both that found in G. thymalli, a pattern which strongly supports the G. thymalli grouping, and a pattern which is found in all G. salaris from salmon. A number of hypotheses could be put forward to explain this dual pattern. It is possible that a hybridisation event 
could have taken place between G. salaris and G. thymalli, the hybrid form being optimised for survival on rainbow trout. This hybridisation event would have resulted in increased genetic variation, as is seen in the IGS repeat sequences from rainbow trout. The opposite may be true, as suggested previously, in that the rainbow trout form is the ancestral form and new hosts, of either salmon or grayling, have resulted in selection of one pattern type due to adaptive selection, or through genetic drift. If this hypothesis were true, it is unlikely that rainbow trout was the original host on which the rainbow-trout form evolved, as rainbow trout is a relatively recent introduction into Europe from America, and Gyrodactylus salaris has not been found to date in America. A third hypothesis for this 'hybrid' form, is that the pattern found in both G. thymalli, and G. salaris is dynamic, and present in all G. salaris/G. thymalli forms, but in very different frequencies. They are selected for differentially in different hosts, not by genetic drift, but because the different patterns confer some advantage to growth or survival on the hosts, either through direct selection pressure on the ribosomal unit itself, or through its linkage to another gene that responds to host-selection pressure. Changes in frequencies of IGS repeat patterns within individuals, in response to selection pressure, have been observed in a number of organisms, including maize Zea mays L., where grain yield is selected for under different environmental conditions (Rocheford 1994, Kaufman et al. 1996), and in Drosophila, where shorter developmental time is selected for (Cluster et al. 1987). The 'hybrid' pattern seen in rainbow trout may be indicative of relaxed selection, or of a co-dominant mixture of rRNA, or associated/linked genes, which give best survival of the parasite on the rainbow trout. If this third hypothesis were true, then the selection for the G. thymalli IGSV type, and any associated genes, would seem to be irreversible, as G. thymalli does not seem to be able to survive or reproduce on rainbow trout under laboratory conditions (T. A. Mo unpubl.). This hypothesis is also supported by the fact that, despite rainbow trout and salmon occurring in the same rivers as grayling infected with G. thymalli in the UK, intensive sampling of salmonids has not provided any evidence of the parasite on the 2 former fish species (Denham \& Long 1999), or of the emergence of a pathogenic G. salaris type.

It may be tempting to hypothesise that the rainbowtrout form of Gyrodactylus salaris is less pathogenic to salmon than G. salaris sensu stricto, particularly as variants of $G$. salaris have shown this trait (Lindenstrøm et al. 2003). The parasites in this study showed identical ITS sequences, unlike those found by Lindenstrøm et al. (in press), and aquarium infections indicate that G. salaris from rainbow trout are indeed pathogenic to salmon (T. A. Mo unpubl.). Therefore, there is no convincing evidence that these Swedish rainbowtrout form samples present a lower threat to salmon than the form found in Norway.

\section{Gyrodactylus salaris populations}

The generally low variation seen in the IGS sequences from salmon samples has prevented rigorous epidemiological analysis, and it is likely that the IGS is too conserved to prove very useful in examining the recent spread of this parasite. Other regions of the genome, such as the mitochondrial DNA (Meinilä et al. 2002), may be more suitable for this purpose. Nevertheless, some important trends can be seen. Visual examination of the alignment indicated that the Swedish samples were more diverse than the Norwegian ones. This is also seen in the phylogenetic trees. This pattern is wholly consistent with the recent and limited introduction of Gyrodactylus salaris to Norway in the 1970s, which will have created extreme genetic bottlenecks and resulted in restricted genetic diversity of the parasite in Norway. This effect has been predicted in fish farms using frequent chemical treatments (Malmberg 1987b), but has not been demonstrated before. No differences have been found here in samples collected pre- (Batnfjordselva, Lærdalselva, Driva) or post- (Skibotnelva, Steinkjervassdr., Rauma) rotenone treatment.

Genetic analysis of populations of Atlantic salmon in Sweden have distinguished fish from the Ätran system from those in the Fylleån (Stahl 1986), and demonstrated a marked variation between populations in rivers of the Ätran, Säveån, Stensån and Genevadsån, which have the Atlantic haplotype, from populations in the Fylleån and Rönne å, which have the Baltic haplotype (Nilsson et al. 2001). There is no clear correlation between the groupings of host populations and the genetic variations in the IGS of $G$. salaris from these hosts. It may be the case that genetic variations in the parasites demonstrated in this study reflect founder effects in these populations rather than genetic drift or adaptation to different host populations. This study has not found any clear link between the IGS groups of parasites and the host haplotype, nor has it found any correlation with the date of infection or sampling. Further genetic markers are required to obtain this level of detail.

In conclusion, analysis of the IGS of Gyrodactylus has confirmed the separation of $G$. salaris and $G$. thymalli, and can be used to discriminate G. salaris rainbow-trout and salmon forms. However, it is not sufficiently variable to analyse populations of $G$. salaris that have been recently separated, such as those from Sweden, Norway, Finland and Russia. Other genetic markers may be more suitable for this purpose. 
Acknowledgements. The authors wish to thank Dr Eugene Ieshko, Russian Academy of Science Karelian Research Centre, Dr Perttu Koski, National Veterinary and Food Research Institute Regional Laboratory, Oulu, Finland, and Dr Sven Bergmann, Federal Rsearch Center for Virus Diseases of Animals, Insel Riems, Germany, for samples of Gyrodactylus salaris. This work was partly funded by the EC FAIR project PL97-3406.

\section{LITERATURE CITED}

Bakke TA (1991) A review of the inter- and intraspecific variability in salmonid hosts to laboratory infections with Gyrodactylus salaris Malmberg. Aquaculture 98:303-310

Bakke TA, Jansen PA, Hansen LP (1990) Differences in the host resistance of Atlantic salmon, Salmo salar, L., stocks to the monogenean Gyrodactylus salaris Malmberg, 1957. J Fish Biol 37:577-587

Bakke TA, Jansen PA, Kennedy CR (1991) The host specificity of Gyrodactylus salaris Malmberg (Platyhelminthes, Monogenea): susceptibility of Oncorhychus mykiss (Walbaum) under experimental conditions. J Fish Biol 39:45-57

Bakke TA, Soleng A, Harris PD, Hansen LP (1996) Gyrodactylid infection of pure Atlantic salmon Salmo salar and brown trout Salmo trutta and their hybrid progeny. VII European Multicolloquium of Parasitology, Parma, Italy. Parassitologia 38:27

Bakke TA, Soleng A, Harris PD (1999) The susceptibility of Atlantic salmon (Salmo salar L.) $\times$ brown trout (Salmo trutta L.) hybrids to Gyrodactylus salaris Malmberg and Gyrodactylus derjavini Mikailov. Parasitol 119:467-481

Burke T, Hanotte O, Bruford MW, Cairns E (1991) Multilocus and single locus minisatellite analysis in population biological studies. In: Burke T, Dolf GA, Jeffreys AJ , Wolf R (eds) DNA fingerprinting: approaches and applications. Birkhauser Verlag, Basel, p 154-168

Collins CM, Cunningham CO (2000) Characterisation of the Gyrodactylus salaris Malmberg, 1957 (Platyhelminthes: Monogenea) ribosomal intergenic spacer (IGS) DNA. Parasitology 121:555-563

Cluster PD, Marinkovic R, Allard RW, Ayala FJ (1987) Correlations between development rates, enzyme activities, ribosomal DNA spacer-length phenotypes, and adaptation in Drosophila melanogaster. Proc Natl Acad Sci USA 84: 610-614

Cunningham CO (1997) Species variation within the internal transcribed spacer (ITS) region of Gyrodactylus (Monogenea; Gyrodactylidae) ribosomal RNA genes. J Parasitol 83:215-219

Cunningham CO, Mo TA (1997) Random amplified polymorphic DNA (RAPD) analysis of three Norwegian populations of Gyrodactylus salaris (Monogenea; Gyrodactylidae). J Parasitol 83:311-314

Cunningham CO, McGillivray DM, MacKenzie K, Melvin WT (1995) Discrimination between Gyrodactylus salaris, G. derjavini and G. truttae (Platyhelminthes: Monogenea) using restriction fragment length polymorphisms and an oligonucleotide probe within the small subunit ribosomal RNA gene. Parasitology 111:87-94

Cunningham CO, Mo TA, Collins CM, Buchmann K, Thiery R, Blanc G, Lautraite A (2001) Redescription of Gyrodactylus teuchis Lautraite, Blanc, Thiery, Daniel \& Vigneulle, 1999 (Monogenea: Gyrodactylidae), a species identified by ribosomal RNA sequence. Syst Parasitol 48:141-150

Denham KL, Long J (1999) Occurrence of Gyrodactylus thymalli Zitnan, 1960 on grayling, Thymallus thymallus (L.), in England. J Fish Dis 22:247-252

Ergens R (1983) Gyrodactylus from Eurasian freshwater Salmonidae and Thymallidae. Folia Parasitol 30:15-26

Ieshko EP, Berland B, Shulman BS, Brostow GA, Shurov IL (1995) Parasites of Atlantic salmon parr in some karelian rivers flowing into the White Sea. Fourth Int Symp Ichthyoparasitology, University of Munich, p 100

Jensen KW, Vik R, Håstein $T$, Gjedrem T, Rosseland BO (1983) The Gyrodactylus project: Report from the Gyrodactylus Committee on Activities in 1982. Agricultural College, Ås

Karlsson L, Kollberg S, Olstad K, Mo TA, Perä I (2003) Gyrodactylus salaris in Swedish rivers - what is the possible impact on wild salmon? Working Group on North Atlantic Salmon, Working Paper 24:1-16

Kaufman B, Rocheford TR, Lambert RJ, Hallauer AR (1996) Change in ribosomal DNA spacer-length composition in maize recurrent selection populations. 2. Analysis of BS10, BS11, RBS10, and RSSSC. Theor Appl Genet 92:680-687

Keranen AL, Koski P, Kulonen K, Ek-Kommonen C, Neuvonen $E$ (1992) Occurrence of infectious fish diseases in fish farms in northern Finland. Acta Veterinaria Scandinavica 33:161-167

Koski P, Malmberg G (1995) Occurrence of Gyrodactylus (Monogenea) on salmon and rainbow trout in fish farms in Northern Finland. Bull Scand Soc Parasitol 5:76-88

Lindenstrøm T, Collins CM, Bresciani J, Cunningham CO, Buchmann K (2003) Characterisation of a Gyrodactylus salaris variant: infection biology, morphology and molecular genetics. Parasitology 127:165-178

Maddison DR, Maddison WP (2000) MacClade 4: Analysis of phylogeny and character evolution. Sinauer Associates, Sunderland, MA

Malmberg G (1957) Om forekomsten av Gyrodactylus pa svenska fiskar. In: Gustafson T, Silén L (eds) Skrifter Utgivna av Sodra Sveriges Fiskeriforening, Arsskrift 1956, Almqvist \& Wiksell, Stockholm, p 19-76

Malmberg G (1970) The excretory systems and the marginal hooks as a basis for the systematics of Gyrodactylus (Trematoda, Monogenea). Arkiv for Zoologi Serie 2 23:235

Malmberg G (1973) Gyrodactylus infestations on species of Salmo in Danish and Swedish hatcheries. Norw J Zool 21: 325-326

Malmberg G (1987a) Gyrodactylus salaris Malmberg 1957 and G. truttae Gläser 1974 -two problematic species. Abo Akademi Information 19:34

Malmberg G (1987b) Increased intraspecific divergence in Gyrodactylus salaris resulting from genetic drift in fish farm populations. Abo Akademi Information 19:33

Malmberg G (1988) Salmonid transports, culturing and Gyrodactylus infections in Scandinavia. Parasites of freshwater fishes of North-west Europe. USSR Academy of Sciences International Symposium. Zoological Institute, USSR Academy of Sciences, Petrozavodsk, p 88-104

Malmberg G (1991) On the spread of Gyrodactylus salaris Malmberg, 1957 and G. derjavini Mikailov, 1975 (Monogenea) in Swedish salmon rivers. Bull Scand Soc Parasitol 1:69

Malmberg G (1993) Gyrodactylidae and gyrodactylosis of salmonidae. Bull Fr Pêche Pisc 328:5-46

Malmberg G, Malmberg M (1987) Gyrodactylus in salmon and rainbow trout farms. Zoo-tax symposium: parasites and diseases in natural waters and aquaculture in Nordic countries. Naturhistoriska Riksmuseets Reprocentral, Stockholm, p 199-204

Malmberg G, Malmberg M (1991) Investigations on Gyrodactylus on salmonids in nature and in hatcheries in 
1951-72 and 1986-May 1991. Information från Sötvattenslaboratoriet, Drottningholm 2:1-130 (in Swedish)

Malmberg G, Malmberg M (1993) Species of Gyrodactylus (Platyhelminthes, Monogenea) on salmonids in Sweden. Fish Res 17:59-68

McHugh ES, Shinn AP, Kay JW (2000) Discrimination of the notifiable pathogen Gyrodactylus salaris from G. thymalli (Monogenea) using statistical classifiers applied to morphometric data. Parasitol 121:315-323

Meinilä M, Kuusela J, Zietara M, Lumme J (2002) Primers for amplifying approximately $820 \mathrm{bp}$ of highly polymorphic mitochondrial COI gene of Gyrodactylus salaris. Hereditas 137:72-74

Mo TA (1991a) Seasonal variations of opisthaptoral hard parts of Gyrodactylus salaris Malmberg, 1957 (Monogenea: Gyrodactylidae) on parr of Atlantic salmon Salmo salar L. in the River Batnfjordselva, Norway. Syst Parasitol 19: 231-240

Mo TA (1991b) Variations of opisthaptoral hard parts of Gyrodactylus salaris Malmberg, 1957 (Monogenea: Gyrodactylidae) on parr of Atlantic salmon Salmo salar L. in laboratory experiments. Syst Parasitol 20:11-19

Mo TA (1991c) Variations of opisthaptoral hard parts of Gyrodactylus salaris Malmberg, 1957 (Monogenea: Gyrodactylidae) on rainbow trout Oncorhynchus mykiss (Walbaum, 1792) in a fish farm, with comments on the spreading of the parasite in South-eastern Norway. Syst Parasitol 20:1-9

Mo TA (1994) Status of Gyrodactylus salaris problems and research in Norway. In: Pike AW, Lewis JW (eds) Parasitic Diseases of Fish. Samara Publishing, Dyfed, p 43-56

Mo TA, Norheim K (2003) The surveillance and control programme for Gyrodactylus salaris in Atlantic salmon and rainbow trout in Norway: Annual report 2002. In: Heier BT (ed) Surveillance and control programmes for terrestrial and aquatic animals in Norway. Annual Report 2002, National Veterinary Institute, Oslo, p 137-141

Morales-Hojas R, Post RJ, Cheke RA, Wilson MD (2002) Assessment of rDNA IGS as a molecular marker in the Simulium damnosum complex. Med Vet Entomol 16: 395-403

Nilsson J, Gross R, Asplund T, Dove O and 7 others (2001)

Editorial responsibility: Wolfgang Körting,

Hannover, Germany
Matrilinear phylogeography of Atlantic salmon (Salmo salar L.) in Europe and postglacial colonization of the Baltic Sea area. Mol Ecol 10:89-102

Rintamaki P (1989) Gyrodactylus salaris at a fish farm in Northern Finland. In: Bauer ON (ed) Parasites of freshwater fishes of north-west Europe. Materials of the International Symposium within the program of the SovietFinnish Cooperation. Institute of Biological Academy of Sciences, Karelia Petrozavodsk, USSR, p 123-130

Rintamaki-Kinnunen P, Valtonen ET (1996) Finnish salmon resistant to Gyrodactylus salaris: a long-term study at fish farms. Int J Parasitol 26:723-732

Rocheford TR (1994) Change in ribosomal DNA intergenic spacer-length composition in maize recurrent selection populations. 1. Analysis of BS13, BSSS, and BSCB1. Theor Appl Genet 88:541-547

Shulman BS, Ieshko EP, Shchurov IL (1998) Infestation of young salmon (Salmo salar L.) by Gyrodactylus salaris Malmberg, 1957, in the river Keret (the North Karelia). In: (eds) Parasites and diseases of marine and fresh water fishes of the North Basin: selected papers. PINRO Press, Murmansk, p 97-102

Stahl G (1986) Genetic population structure of Atlantic salmon. In: Ryman N , Utter F (eds) Population genetics \& fishery management. University of Washington Press, Seattle, p 121-140

Sterud E, Mo TA, Collins CM, Cunningham CO (2002) The use of host specificity, pathogenicity, and molecular markers to differentiate between Gyrodactylus salaris Malmberg, 1957 and G. thymalli Zitnan, 1960 (Monogenea: Gyrodactylidae). Parasitol 124:203-214

Swofford DL (2002) PAUP*. Phylogenetic Analysis Using Parsimony ( ${ }^{*}$ and Other Methods). Version 4. 4.0b10. Sinauer Associates, Sunderland, MA

Thompson JD, Gibson TJ, Plewniak F, Jeanmougin F, Higgins DG (1997) The CLUSTAL_X windows interface: flexible strategies for multiple sequence alignment aided by quality analysis tools. Nucleic Acids Res 25:4876-4882

Zietara M, Lumme J (2003) The crossroads of molecular, typological and biological species concepts: two new species of Gyrodactylus Nordmann, 1832 (Monogenea: Gyrodactylidae). Syst Parasitol 55:39-52

Submitted: July 23, 2003; Accepted: August 25, 2003

Proofs received from author(s): December 15, 2003 